\title{
Sofosbuvir in combination with ribavirin or simeprevir: real-life study of patients with hepatitis C genotype 4
}

\author{
Adel Abdel-Moneima ${ }^{a}$, Alaa Aboud ${ }^{b}$, Mohamed Abdel-Gabbarc, Mohamed I. Zanaty ${ }^{d}$, \\ Amr A. Abd Elbary', Mohamed Ramadanc
}

University of Beni-Suef, Egypt

\section{Abstract}

\section{Introduction}

Hepatitis C virus (HCV) imposes a major disease burden worldwide and is one of the major causes of death related to chronic liver disease [1]. Untreated HCV can lead to cirrhosis, liver failure, and hepatocellular carcinoma, resulting in up to 500,000 related deaths per year [2]. Egypt has the highest burden of advanced liver

aDivision of Molecular Physiology, Faculty of Science (Adel AbdelMoneim); ${ }^{b}$ Department of Tropical Medicine, Faculty of Medicine (Alaa Aboud,Amr A. Abd Elbary); 'Division of Biochemistry, Faculty of Science (Mohamed Abdel-Gabbar, Mohamed Ramadan); ${ }^{\mathrm{d} D e p a r t m e n t}$ of Biotechnology, Faculty of Postgraduate Studies for Advanced Science (Mohamed I. Zanaty), University of Beni-Suef, Egypt

Conflict of Interest: None

Correspondence to: Prof. Adel Abdel-Moneim, PhD, Salah Salim St., 62511, Beni-Suef, Egypt, e-mail: adel_men2020@yahoo.com \& adel. hassan@science.bsu.edu.eg

Received 27 August 2018; accepted 11 October 2018; published online 24 November 2018

DOI: https://doi.org/10.20524/aog.2018.0327 disease from HCV globally, and estimates suggest that in Egypt in 2013 there were 770,000 persons with cirrhosis, 16,000 HCVrelated hepatocellular carcinoma cases, and 33,000 HCV-related liver deaths [3]. The genotype 4 (GT4) strain of HCV accounts for approximately $20 \%$ of all patients with chronic hepatitis C (CHC) worldwide [4]. In Egypt, GT4 accounts for approximately 90\% of infections, with subtype 4a predominating [5].

Recently, direct antiviral agents (DAA) have revolutionized the treatment of $\mathrm{CHC}$ and the approval of sofosbuvir (SOF) represents the first key step towards a new era in the management of CHC patients [6]. The approval of an interferon (IFN)-free regimen for CHC GT4 infection has the potential to impact on the incidence and burden of $\mathrm{CHC}$, particularly in Egypt where the prevalence of CHC GT4 is so high. Several countries have launched national plans aimed to eradicate HCV infection through provision of a universal treatment for all $\mathrm{HCV}$-infected patients. Globally, 1.76 million people received treatment for infection with HCV in 2016. Moreover, in 2017, treatment access increased further as several low- and middle-income countries continued to roll out DAA therapy-notably Egypt, which alone accounted for almost $40 \%$ of people who started CHC treatment globally in 2016. Egypt's comprehensive national testing and 
treatment program and domestic production of low-cost generic DAAs (SOF-based treatments) enabled rapid treatment, with the number of people receiving DAAs rising from 30,000 in 2014 to 700,000 in 2016. Additionally, by September 2017, a cumulative total of 1.5 million people had received HCV treatment [7].

SOF is an oral HCV-specific NS5B nucleotide polymerase inhibitor with potential therapeutic efficacy in $\mathrm{CHC}$ patients with G1-6 [8-10]. In the treatment of CHC GT4 infection, it promises a significant improvement in outcomes [9] and is considered an excellent backbone for combination DAA regimens [11]. Treatment with SOF plus simeprevir (SMV), an NS3A (non-structural protein $3 \mathrm{~A})$ protease inhibitor, achieved high rates of sustained virological response (SVR12) in CHC GT4 patients [12]. SMV, approved by the USA's Food and Drug Administration (FDA) in November 2013, has also been approved in the European Union for the treatment of CHC GT4 infection, both in combination with pegIFN plus ribavirin (RBV) and in IFN-free regimens in combination with SOF, with or without RBV [13]. Thus, these combinations DAA regimens have confirmed their efficacy in treatment-naïve, treatment-experienced, non-cirrhotic and cirrhotic patients [14]. However, efficacy and safety data regarding DAA regimens in $\mathrm{CHC}$ GT4 patients are currently scarce. Thus, the current investigation aimed to determine the therapeutic efficacy of 2 SOF-based regimens i.e., SOF plus RBV vs. SOF plus SMV, in the treatment of Egyptian patients with CHC GT4.

\section{Patients and methods}

\section{Study design and patient population}

This real-life study was conducted in some treatment centers at Beni Suef, Egypt. A cohort of 201 patients with CHC GT4 infection was allocated to complete the treatment course between April 2015 and July 2016. The study was approved by each center's institutional review board and written consent was obtained from all patients. Additionally, the study protocol complied with Egyptian National Guidelines and was performed in accordance with the Declaration of Helsinki and Good Clinical Practice guidelines (Decision: BSU/2015/3/27).

Treatment-naïve and experienced adult patients were at least 18 years old and had CHC GT4 infection, with a plasma HCV RNA level $>10,000$ IU/L. Patients were classified into 2 groups based on treatment type, group 1 (SOF/RBV) and group 2 (SOF/SMV), their eligibility is based on the criteria of the approved treatment recommendations [15]. Treatmentexperienced patients in group 1 (48 patients) were those who had previously failed treatment with classical peg-IFN/RBV therapy. Group 2 (25 patients) included experienced patients who had previously failed treatment with SOF/RBV regimen (18 patients) or SOF/peg-IFN/RBV therapy (7 patients), i.e., failure of DAA treatments. Fibrosis stage was diagnosed using data from ultrasonographic examination, FIB-4 score, serum albumin $<3.5$, and total bilirubin $>1.2 \mathrm{mg} /$. Also, if available, liver biopsy or liver stiffness by FibroScan of $>12.5 \mathrm{kPa}$ were used.

Patients were excluded if they were coinfected with hepatitis $B$ virus or human immunodeficiency virus infection, or had any cause of liver disease other than CHC GT4 infection; patients with a clinical history of liver decompensation, evidence of hepatocellular carcinoma, or major severe illness, such as renal failure, congestive heart failure, thyroid dysfunction, respiratory failure, autoimmune disease and poorly controlled diabetes (HbA1C >9), were also excluded. In addition, patients with blood picture abnormalities, such as anemia (hemoglobin concentration of $10 \mathrm{~g} /$ or less) and thrombocytopenia (platelet count $<50,000$ cells $/ \mathrm{mm}^{3}$ ) were excluded.

\section{Study treatment}

SOF (Sovaldi) was given in a dose of $400 \mathrm{mg} /$ day in both groups. Additionally, in group 1, RBV was given orally in the morning and in the evening (total daily dose was based on body weight: $<75 \mathrm{~kg}, 1000 \mathrm{mg} ;>75 \mathrm{~kg}, 1200 \mathrm{mg}$ ). Patients receiving dual DAA treatment (group 2) were given SMV orally as a single $150 \mathrm{mg}$ q.d. capsule. The endpoint was SVR12, defined as HCV RNA <15 IU/mL undetectable at 12 weeks after planned end of treatment (EOT). Viral relapse was HCV RNA $<15 \mathrm{IU} / \mathrm{mL}$ undetectable at EOT, but detectable HCV RNA $>15 \mathrm{IU} / \mathrm{mL}$ levels at 12 weeks after planned EOT (Fig. 1).

\section{Assessment of safety}

Safety was assessed through the monitoring of patients' examinations during treatment periods and follow up 12 weeks after planned EOT. Adverse events (AEs) were recorded based on clinical examinations and laboratory test results throughout the study course and during follow up for 12 weeks after planned EOT. AEs and laboratory biochemical and hematological abnormalities were graded according to the World Health Organization's grading scale.

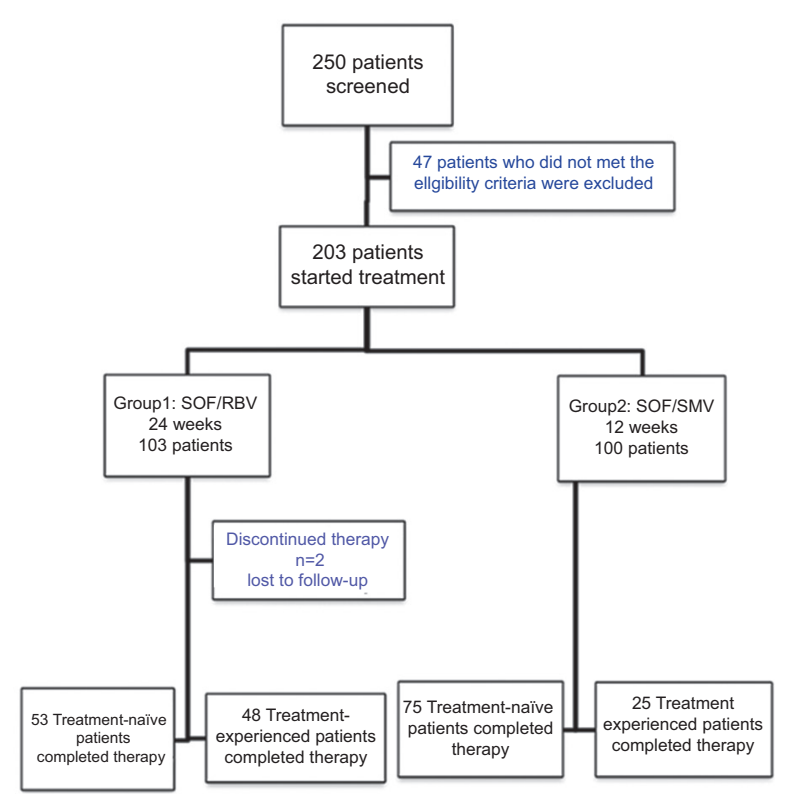

Figure 1 Patient disposition and the study design 


\section{Laboratory assessment}

FIB-4 was determined according to the equation of Sterling et al [16], FIB-4 score $<1.45-3.25=$ F0-2 (none or moderate fibrosis) and FIB- 4 score $>3.25=$ F3 -4 (advanced fibrosis or cirrhosis). CHC GT4 genotyping at screening was assessed by the VERSANTHCV Genotype 2.0 Assay (LiPA) (Siemens, Germany). Also, genotyping for the IL-28B rs12979860 C/T polymorphism was performed using a polymerase chain reaction-based restriction fragment length polymorphism (PCR-RFLP) assay. HCV RNA was analyzed by quantitative PCR (qPCR), using a Roche Amplicor HCV monitor version 2.0 (Roche Molecular Systems, Inc., Branchburg, NJ) with lower detection limit $<15 \mathrm{IU} / \mathrm{mL}$. Hematological parameters were determined using a MICROS $\mathrm{ABX}$ autoanalyzer according to the manufacturer's protocol.

\section{Statistical analysis}

Data are expressed as mean \pm standard deviation (SD) or median and number (percentage) for categorical data. The virological response was based on modified intention-to-treat" (mITT) or "per-protocol" analysis. Student's $t$-test was used for comparisons. The Statistical Package for Social Science (SPSS) version 20 software was used for the analysis. Values of $\mathrm{P}<0.05$ were considered significant.

\section{Results}

\section{Patient characteristics}

A total of 250 patients were screened in some centers at Beni Suef, Egypt.Of these, 47 patients were excluded because they did not meet the eligibility criteria. Of the 203 patients who started treatment, 201 patients completed the treatment period and all investigations, whereas 2 patients were lost to follow up. Eligible patients were categorized into 2 groups: group 1 (SOF/RBV) included 101 patients, while group 2 (SOF/SMV) included 100 patients. Of the enrolled patients, $84 \%$ and $81 \%$ had CHC GT4a infection, and $74 \%$ and $72 \%$ IL28B subtype non-CC in groups 1 and 2, respectively. According to FIB-4 score, group 1 screening showed that $25 \%$ of patients had advanced fibrosis (F3-4), compared with $22 \%$ in group 2. During the study period, no patients had serious AEs leading to discontinuation (Tables $1 \& 2$, Fig. 1).

\section{Antiviral response (efficacy)}

Among the patients of group 1, SVR12 was achieved by $89 \%(90 / 101)$ of all patients receiving SOF/RBV for 24 weeks, 92\% (49/53) of naïve patients and 85\% (41/48) of experienced patients.Among the patients treated with $\mathrm{SOF} /$ SMV for 12 weeks, SVR12 rate was achieved 92\% (92/100) of all patients, by $93 \%(70 / 75)$ of naïve patients and by $88 \%(22 / 25)$
Table 1 Demographic and laboratory data of patients receiving SOF/ RBV for 24 weeks

\begin{tabular}{|c|c|c|c|}
\hline Parameters (n) & $\begin{array}{c}\text { Overall } \\
\text { baseline } \\
101\end{array}$ & $\begin{array}{c}\text { Naïve } \\
\text { baseline } \\
53\end{array}$ & $\begin{array}{c}\text { Experiencec } \\
\text { baseline } \\
48\end{array}$ \\
\hline Age, years (Mean) & 48.56 & 50.35 & 47.62 \\
\hline (SD) & 9.73 & 9.48 & 8.21 \\
\hline $\operatorname{Sex}(M / F)$ & $(52 / 49)$ & $(31 / 22)$ & $(21 / 27)$ \\
\hline $\begin{array}{l}\text { FIB-4 score, n (\%) } \\
\quad<1.45-3.25 \\
>3.25\end{array}$ & $\begin{array}{l}76(75) \\
25(25)\end{array}$ & $\begin{array}{l}44(83) \\
9(17)\end{array}$ & $\begin{array}{l}32(67) \\
16(33)\end{array}$ \\
\hline $\begin{array}{l}\text { HCV genotype, n (\%) } \\
4 \mathrm{a} \\
4 \mathrm{o} \\
4 \mathrm{~m} \\
4 \mathrm{n} \\
4 \mathrm{c} / \mathrm{d}\end{array}$ & $\begin{array}{c}84(83) \\
8(8) \\
5(5) \\
3(3) \\
1(1)\end{array}$ & $\begin{array}{c}46(87) \\
4(8) \\
2(4) \\
1(2) \\
0\end{array}$ & $\begin{array}{c}38(79) \\
4(8) \\
3(6) \\
2(4) \\
1(2)\end{array}$ \\
\hline $\begin{array}{l}\text { IL28B genotype, n (\%) } \\
\text { CC } \\
\text { CT } \\
\text { TT }\end{array}$ & $\begin{array}{l}17(17) \\
59(59) \\
25(25)\end{array}$ & $\begin{array}{l}10(19) \\
32(60) \\
11(21)\end{array}$ & $\begin{array}{l}7(15) \\
27(56) \\
14(29)\end{array}$ \\
\hline Platelets $<100\left(\times 10^{3}\right) \mathrm{n}(\%)$ & $9(9)$ & $2(4)$ & $7(15)$ \\
\hline Albumin $<3.5 \mathrm{n}(\%)$ & $11(11)$ & $6(11)$ & $5(10)$ \\
\hline $\begin{array}{l}\text { HCV RNA, n (\%) } \\
<800,000 \mathrm{IU} / \mathrm{mL}\end{array}$ & $83(82)$ & $45(85)$ & $39(81)$ \\
\hline $\begin{array}{l}\text { HCV RNA, n (\%) } \\
>800,000 \mathrm{IU} / \mathrm{mL}\end{array}$ & $18(18)$ & $4(15)$ & $9(19)$ \\
\hline
\end{tabular}

of experienced patients. Regarding treatment failure, group 1 recorded 11 patients with treatment failure after 24 weeks of treatment, while group 2 reported 9 patients with treatment failure (Fig. 2). The 6 patients who had relapses in group 1 received the full dose of the treatment: 3 patients had GT4a, 2 GT4o and 1 GT4n, while 2 patients had IL-28B subtype CC and 4 had none-CC. In addition, 2 patients were non-cirrhotic whereas 4 had cirrhosis, and the 4 experienced patients had been treated previously with peg-IFN/RBV. The 5 patients who had a relapse in group 2 completed the treatment course: 3 patients had GT4a, and 2 GT4o, while 2 patients had IL-28B subtype CC and 3 had none-CC (Table S1). One patient was non-cirrhotic and the other 4 patients were cirrhotic. The 2 experienced patients had been treated previously with SOF/RBV. Among the cirrhotic patients, virological failure was recorded in $16 \%$ of the SOF/RBV group and $14 \%$ of the SOF/SMV group, while for non-cirrhotic patients the respective rates were $9 \%$ and $6 \%$ (Table S2).

The present study showed that the treatment of both SOF/RBV and SOF/SMV achieved significant amelioration in transaminase activity (both alanine and aspartate aminotransferases) as a response to viral elimination and clearance. On the other hand, hemoglobin concentration showed a significant decrease only in patients of group 1 (Table S3). 
Table 2 Demographics, laboratory abnormalities of patients receiving SOF/SMV for 12 weeks

\begin{tabular}{|c|c|c|c|}
\hline Parameters (n) & $\begin{array}{c}\text { Overall } \\
\text { baseline } \\
100\end{array}$ & $\begin{array}{c}\text { Naïve } \\
\text { baseline } \\
75\end{array}$ & $\begin{array}{c}\text { Experience } \\
\text { baseline } \\
25\end{array}$ \\
\hline Age, years (Mean) & 47.72 & 47.14 & 49.34 \\
\hline (SD) & 9.79 & 9.77 & 9.84 \\
\hline $\operatorname{Sex}(M / F) n$ & $(57 / 43)$ & $(40 / 35)$ & $(15 / 10)$ \\
\hline $\begin{array}{l}\text { FIB-4 score, } \mathrm{n}(\%) \\
\quad<1.45-3.25 \\
>3.25\end{array}$ & $\begin{array}{l}78(78) \\
22(22)\end{array}$ & $\begin{array}{l}61(81) \\
14(19)\end{array}$ & $\begin{array}{l}17(68) \\
8(32)\end{array}$ \\
\hline $\begin{array}{l}\text { HCV genotype, n (\%) } \\
4 \mathrm{a} \\
4 \mathrm{o} \\
4 \mathrm{~m} \\
4 \mathrm{n} \\
4 \mathrm{c} / \mathrm{d}\end{array}$ & $\begin{array}{c}81(81) \\
10(10) \\
3(3) \\
4(4) \\
2(2)\end{array}$ & $\begin{array}{c}63(84) \\
7(10) \\
2(3) \\
2(3) \\
1(1)\end{array}$ & $\begin{array}{l}18(72) \\
3(12) \\
1(4) \\
2(8) \\
1(4)\end{array}$ \\
\hline $\begin{array}{l}\text { IL28B genotype, n (\%) } \\
\text { CC } \\
\text { CT } \\
\text { TT }\end{array}$ & $\begin{array}{l}20(20) \\
61(61) \\
19(19)\end{array}$ & $\begin{array}{l}16(21) \\
46(61) \\
13(17)\end{array}$ & $\begin{array}{c}4(16) \\
15(60) \\
6(24)\end{array}$ \\
\hline Platelets $<100\left(\times 10^{3}\right) \mathrm{n}(\%)$ & $7(7)$ & $1(1)$ & $6(24)$ \\
\hline Albumin $<3.5 \mathrm{n}(\%)$ & $10(10)$ & $5(7)$ & $5(20)$ \\
\hline $\begin{array}{l}\text { HCV RNA, n (\%) } \\
<800,000 \mathrm{IU} / \mathrm{mL}\end{array}$ & $85(85)$ & $67(89)$ & $18(72)$ \\
\hline $\begin{array}{l}\text { HCV RNA, n (\%) } \\
>800,000 \mathrm{IU} / \mathrm{mL}\end{array}$ & $15(15)$ & $8(11)$ & $7(28)$ \\
\hline
\end{tabular}

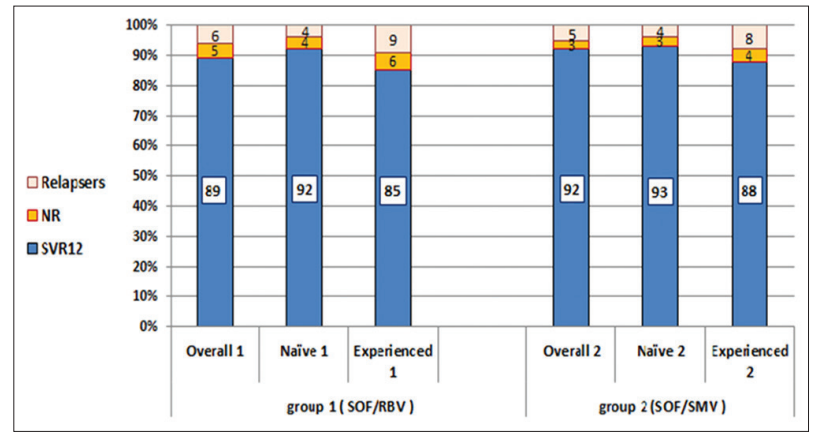

Figure 2 Percentages of overall, treatment-naïve and treatmentexperienced patients who achieved SVR12 after treatment with SOF/ RBV (Group 1) and SOF/SMV (Group 2)

SOF, sofosbuvir; SMV, simeprevir; RBV, ribavirin; $N R$, non-response; SVR12 sustained virological response 12 weeks after the end of treatment

\section{Safety assessments}

Adverse events (AEs) were reported in $70 \%$ and $42 \%$ of patients in groups 1 and 2, respectively, and generally were mild and transient. The most common AEs in both groups included fatigue, headache, nausea, and dyspnea. Other AEs reported in the SOF/SMV group included rash (14\%), photosensitivity (8\%) and hyperbilirubinemia (6\%). Other AEs recorded in the SOF/
RBV group were more related to decreasing hemoglobin level (anemia) (33/101, 32.7\%), insomnia (11/101, 10.9\%), and influenza-like illness (10/101, 9.9\%). Serious AEs were reported in 1 patient in the SOF/SMV group (hospitalized because of photosensitivity) and 2 patients in the SOF/RBV group (hospitalized because of severe anemia and treated without blood transfusion). No patients had serious AEs leading to discontinuation during the study (Fig. 1, Table 3).

\section{Discussion}

Achievement of an undetectable viral load is associated with decreased hepatic morbidity and mortality [17]. Therefore, the discovery of DAA was an outstanding achievement of modern medicine in the current century and the approval of SOF by the FDA has opened a new landscape in the management of $\mathrm{CHC}$ [6]. The European Association for the Study of the Liver [EASL] issued 6 guidelines for the treatment of CHC GT4 [15]. In the present study, in patients treated with SOF/RBV, SVR12 rate was achieved by $89 \%$, by $92 \%$ of naïve patients and by $85 \%$ of experienced patients. Among patients receiving SOF/SMV therapy, SVR12 rate was achieved by $92 \%$ of overall patients, by $93 \%$ of naïve patients and by $88 \%$ of experienced patients. Our results were consistent with those of several studies evaluating the treatment of CHC GT4 patients with both SOF/RBV and SOF/SMV regimens [3,12,18-21].

When SOF was given as dual therapy with RBV to $\mathrm{CHC}$ GT4 infected patients of Egyptian origin in the US for 12 weeks, SVR12 rate was achieved by $79 \%$ and by $59 \%$ of treatmentnaïve and experienced patients, respectively [18]. Moreover, the combination of SOF/RBV treatment for 24 weeks in a cohort of Egyptian patients showed an SVR12 rate of 90\%, this cohort included few patients with cirrhosis and the SVR12 rate in those patients was lowered (78\%) [3]. Abd-Elsalam et al [21] reported that, after SOF/RBV treatment of cirrhotic Egyptian patients with CHC GT4, the rate of SVR12 was higher in the naïve group receiving treatment for 24 weeks (92\%) vs. 12 weeks (84\%), while in treatment-experienced subjects the rate of SVR12 was $89 \%$ vs. $70 \%$ in the two groups who received treatment for 24 and 12 weeks, respectively. RBV in combination with DAA still retains an important role in the optimal treatment of some subgroups of patients, particularly those that historically have been considered the most difficult to cure [22].

The results of our study are comparable with those of Hanno et al [12] regarding treatment with SOF/SMV for 12 weeks, which showed a high rate of SVR12 among treatment-naïve and experienced patients with CHC GT4. The authors also mention that daily treatment with SMV/SOF for 12 and 24 weeks for CHC GT4-infected Egyptian patients achieved an SVR12 rate of $100 \%$ and an SVR24 rate of $96.6 \%$ for cirrhotic and noncirrhotic patients. Eletreby et al [23] reported that, in a cohort of Egyptian patients who received SMV/SOF combination therapy for treatment of CHC GT4, SVR12 was achieved by $94 \%$ in the overall study population the SVR 12 rate was $93 \%$ in the difficult-to-treat group and $96 \%$ in the easy-to-treat group. Furthermore, El Raziky et al [24] revealed that treatment with SMV plus SOF for 12 weeks was a highly effective (92-100\%) 
Table 3 AEs and laboratory abnormalities of overall patients receiving SOF/RBV and SOF/SMV regimens

\begin{tabular}{|c|c|c|}
\hline Side effect & $\begin{array}{l}\text { SOF/RBV } \\
101 \text { patients }\end{array}$ & $\begin{array}{l}\text { SOF/SMV } \\
100 \text { patients }\end{array}$ \\
\hline Any AEs during treatment (n) & 71 & 42 \\
\hline AEs leading to discontinuation (n) & 0 & 0 \\
\hline Serious adverse events (n) & 2 & 1 \\
\hline $\begin{array}{l}\text { Common AEs (n) } \\
\text { Fatigue }\end{array}$ & 30 & 17 \\
\hline Headache & 26 & 12 \\
\hline Nausea & 21 & 11 \\
\hline Dyspnea & 18 & 9 \\
\hline $\begin{array}{l}\text { Influenza-like illness } \\
\text { (fever, myalgia, rigors) }\end{array}$ & 10 & 6 \\
\hline Insomnia & 11 & 4 \\
\hline Rash (any type) & 8 & 14 \\
\hline Diarrhea & 5 & 3 \\
\hline Photosensitivity & 0 & 8 \\
\hline Laboratory abnormalities (n) & & \\
\hline Anemia & 33 & 0 \\
\hline Thrombocytopenia & 2 & 0 \\
\hline Leukopenia & 1 & 1 \\
\hline Elevated bilirubin & 2 & 6 \\
\hline Elevated alanine aminotransferase & 1 & 0 \\
\hline Elevated aspartate aminotransferase & 0 & 1 \\
\hline
\end{tabular}

and well-tolerated regimen for CHC GT4 in both treatmentnaïve and experienced patients with F0-4 fibrosis.

The present data obtained from naïve and experienced Egyptians patients revealed that relapses occurred in all treated groups after 12 weeks of treatment cessation. The response rates were associated with viral genotypes, ethnicity, and sex [25]. The risk of developing $\mathrm{HCV}$ variants is related to host- and virus-related factors, the properties of the regimens used and the treatment strategies applied [26]. Many of the traditional determinants of response to dual therapy, such as interleukin-28 (IL-28) GT, fibrosis stage, presence or absence of insulin resistance and vitamin $\mathrm{D}$ deficiency, have also been shown to be of importance in the treatment of CHC GT4 infection [27]. The current data on Egyptian patients with CHC GT4 revealed that the IL28B subtype non-CC status of the patients was $83 \%$ and $80 \%$ in groups 1 and 2 , respectively. In parallel with our results, Ruane et al [18] reported that $90 \%$ of Egyptian patients had a subtype GT4a and $88 \%$ had IL28B subtype non-CC status. On the other hand, although protease inhibitors (like SMV) are potent antivirals, they are highly specific, and since the amino acid sequence of the NS3 protease differs significantly between HCV genotypes, protease inhibitors will not have the same efficacy in different genotypes [28]. Viruses resistant to NS3-4A protease inhibitors disappear from peripheral blood in a few weeks to months, whereas NS5A inhibitor-resistant viruses persist for years [29].

In the current study, the treatment-experienced patients in SOF/RBV group were those who had previously failed with peg-IFN/RBV therapy (IFN-based treatment), whereas experienced patients in the SOF/SMV group included those who had previously failed with SOF/RBV and SOF/peg-IFN/RBV therapies (SOF-based treatments). Until recently, retreatment decisions after DAA failure were influenced by HCV drug resistance, the degree of the patient's cirrhosis and the HCV GT. Recommended treatment approaches previously depended on limited clinical trials and expert opinion [30]. Combining DAA with different viral targets and non-overlapping resistance profiles may enhance antiviral activity, which might achieve higher virological response rates for difficult-to-cure populations and allow for shorter durations of treatment. For experienced patients, Buti and Esteban [26] concluded that the most favorable strategy for retreatment of HCV patients is SOF as backbone therapy plus a drug from a class other than that previously used.

Concerning the safety and tolerability profiles in the current study, the main AEs recorded during the treatment course were fatigue, headache, nausea and dyspnea. Additionally, anemia was recorded in the SOF/RBV group while rash, photosensitivity and hyperbilirubinemia were recorded in the SOF/SMV group. The abovementioned AEs were in line with those reported in several previous studies for the two current regimens [12,18,23]. In addition, Jacobson et al [13] concluded that the SOF/RBV regimen showed an optimal tolerability profile; the most frequent AEs were fatigue (44\%), nausea (22\%), headache (21\%), insomnia (19\%) and pruritus (11\%), mainly consistent with RBV. Rates of AEs in the SOF/SMV study were numerically low, and they attributed this result to the lack of RBV [15]. In addition, El Raziky et al reported that SOF/SMV treatment was considered to be a safer and bettertolerated therapy; the few AEs recorded included pruritus, increased lipase activity, and hyperbilirubinemia [24].

The present real-life study suggests that both SOF/RBV and SOF/SMV combination regimens are highly effective in treating CHC GT4. However, SOF/SMV (2 DAAs) combination therapy appears to be well tolerated and effective, with a short treatment duration, and may be a safer treatment choice compared with the SOF/RBV regimen. Our results confirm the need for further efforts to achieve 100\% SVR via the substitution and/or addition of other DAAs to current regimens, especially in difficult-to-treat patients, in order to achieve the dream of HCV eradication in Egypt and the world.

\section{Acknowledgment}

The authors are thankful to the staff member of the treatment centers as well as the Health Affairs Directorate, Beni Suef, Egypt, for the use of their facilities in this study.

\section{References}

1. Thrift AP, El-Serag HB, Kanwa F. Global epidemiology and burden of HCV infection and HCV-related disease. Nat Rev Gastroenterol Hepatol 2017;14:122-132.

2. Mohd Hanafiah K, Groeger J, Flaxman AD, Wiersma ST. Global epidemiology of hepatitis C virus infection: new estimates 


\section{Summary Box}

\section{What is already known:}

- A regimen for chronic hepatitis $\mathrm{C}(\mathrm{CHC})$ that is simple, with few adverse effects and of short duration is critical

- The discovery of direct acting antiviral agents (DAA) is an outstanding achievement of modern medicine in the current century

- The administration of sofosbuvir (SOF) in combination with simeprevir (SMV) or ribavirin (RBV) improved sustained virological response (SVR12) rates among CHC patients

\section{What the new findings are:}

- Efficacy and tolerability profile of SOF combined with SMV or RBV to increase SVR12 rates in patients infected with CHC genotype 4 was better understood

- SOF/SMV treatment duration was shortened from 24 weeks of SOF/RBV to 12 weeks

- The SOF/RBV regimen was well tolerated compared to the SOF/RBV regimen

- There is a further need to develop new DAA regimens to achieve $100 \%$ SVR 12

of age-specific antibody to HCV seroprevalence. Hepatology 2013;57:1333-1342.

3. Doss W, Shiha G, Hassany M, et al. Sofosbuvir plus ribavirin for treating Egyptian patients with hepatitis C genotype 4. J Hepatol 2015;63:581-585.

4. Khattab MA, Ferenci P, Hadziyannis SJ, et al. Management of hepatitis $C$ virus genotype 4: recommendations of an international expert panel. J Hepatol 2011;54:1250-1262.

5. Kandeel A, Genedy M, El-Refai S, Funk AL, Fontanet A, Talaat M. The prevalence of hepatitis C virus infection in Egypt 2015: implications for future policy on prevention and treatment. Liver Int 2017;37:45-53.

6. Abdel-Moneim A, Ramadan SH. Medication of chronic hepatitis C: a review on sofosbuvir as a new antiviral drug. ASRJETS 2015;13:1-23.

7. World Health Organization. Progress report on access to hepatitis $\mathrm{C}$ treatment: focus on overcoming barriers in low-and middleincome countries. March 2018. Available from: http://apps.who. int/iris/bitstream/handle/10665/260445/WHO-CDS-HIV-18.4eng.pdf [Accessed on October 27, 2018].

8. Abdel-Moneim A,Aboud A,Abdel-Gabbar M,Zanaty M, Ramadan M. Retreatment efficacy of sofosbuvir/ombitasvir/paritaprevir/ritonavir + ribavirin for hepatitis C virus genotype 4 patients. Dig Dis Sci 2018;63:1341-1347.

9. Lawitz E, Mangia A, Wyles D, et al. Sofosbuvir for previously untreated chronic hepatitis $\mathrm{C}$ infection. $N$ Engl $J$ Med 2013;368:1878-1887.

10. Jacobson IM, Gordon SC, Kowdley KV, et al; FUSION Study. Sofosbuvir for hepatitis C genotype 2 or 3 in patients without treatment options. N Engl J Med 2013;368:1867-1877.

11. Abdel-Moneim A, Aboud A, Abdel-Gabbar M, Zanaty M, Ramadan M. A sofosbuvir-based quadruple regimen is highly effective in HCV type 4-infected Egyptian patients with DAA treatment failure. J Hepatol 2018;68: 1313-1315.

12. Hanno A, Elwazzan D, Ibrahim M, Hafez R. A real life study on treatment of Egyptian patients with HCV genotype IV with simeprevir and sofosbuvir. Health 2016;8:780-786.

13. Medivir AB. Simeprevir approved in the European Union for the treatment of adults with hepatitis $C$ genotype 1 and 4 infection. May 2014. Available from: http://news.cision.com/medivir/r/ simeprevir-approved-in-the-european-union-for-the-treatmentof-adults-with-hepatitis-c-genotype-1-an,c9586720 [Accessed on October 27, 2018].

14. Jensen DM, O'Leary J, Pockros P, et al. Safety and efficacy of sofosbuvir-containing regimens for hepatitis C: real-world experience in a diverse, longitudinal observational cohort. Hepatology 2014;40:219A-220A [Abstract].

15. European Association for the Study of the Liver; EASL recommendations on treatment of hepatitis C 2015. J Hepatol 2015;63:199-236.

16. Sterling RK, Lissen E, Clumeck N, et al. Development of a simple noninvasive index to predict significant fibrosis patients with HIV/ HCV co-infection. Hepatology 2006;43:1317-1325.

17. McCombs J, Matsuda T, Tonnu-Mihara I, et al. The risk of longterm morbidity and mortality in patients with chronic hepatitis C: results from an analysis of data from a Department of Veterans Affairs Clinical Registry. JAMA Intern Med 2014;174:204-212.

18. Ruane PJ, Ain D, Stryker R, et al. Sofosbuvir plus ribavirin for the treatment of chronic genotype 4 hepatitis $C$ virus infection in patients of Egyptian ancestry. J Hepatol 2015;62:1040-1046.

19. Buti M, Calleja JL, Lens S, et al. Simeprevir in combination with sofosbuvir in treatment-naïve and -experienced patients with hepatitis C virus genotype 4 infection: a Phase III, open-label, singlearm study (PLUTO). Aliment Pharmacol Ther 2017;45:468-475.

20. Elsharkawy A, Fouad R, El Akel W, et al. Sofosbuvir-based treatment regimens: real life results of 14409 chronic HCV genotype 4 patients in Egypt. Aliment Pharmacol Ther 2017;45:681-687.

21. Abd-Elsalam S, Sharaf-Eldin M, Soliman S, Elfert A, Badawi R, Ahmad YK. Efficacy and safety of sofosbuvir plus ribavirin for treatment of cirrhotic patients with genotype 4 hepatitis $\mathrm{C}$ virus in real-life clinical practice. Arch Virol 2018;163:51-56.

22. Feld JJ, Jacobson IM, Sulkowski MS, Poordad F, Tatsch F, Pawlotsky JM. Ribavirin revisited in the era of direct-acting antiviral therapy for hepatitis C virus infection. Liver Int 2017;37:5-18.

23. Eletreby R, Elakel W, Said M, et al. Real life Egyptian experience of efficacy and safety of Simeprevir/Sofosbuvir therapy in 6211 chronic HCV genotype IV infected patients. Liver Int 2017;37:534-541.

24. El Raziky M, Gamil M, Ashour MK, et al. Simeprevir plus sofosbuvir for eight or 12 weeks in treatment-naïve and treatmentexperienced hepatitis $C$ virus genotype 4 patients with or without cirrhosis. J Viral Hepat 2017;24:102-110.

25. Kau A, Vermehren J, Sarrazin C. Treatment predictors of a sustained virologic response in hepatitis B and C. J Hepatol 2008;49:634-651.

26. Buti M, Esteban R. Management of direct antiviral agent failures. Clin Mol Hepatol 2016;22:432-438.

27. Antaki N, Bibert S, Kebbewar K, et al. IL28B polymorphisms predict response to therapy among chronic hepatitis $\mathrm{C}$ patients with HCV genotype 4. J Viral Hepat 2013;20:59-64.

28. Asselah T, De Muynck S, Broët P, et al. IL28B polymorphism is associated with treatment response in patients with genotype 4 chronic hepatitis C. J Hepatol 2012;56:527-532.

29. Pawlotsky JM. Hepatitis C virus resistance to direct-acting antiviral drugs in interferon-free regimens. Gastroenterology 2016;151:70-86.

30. Zuckerman A, Chastain CA, Naggie S. Retreatment options following HCV direct-acting antiviral failure. Curr Treat Options Infect Dis 2017;9:389-402. 


\section{Supplementary Table}

Supplementary Table 1 Characteristics of patients with treatment failure receiving SOF/RBV and SOF/SMV regimens

\begin{tabular}{|c|c|c|c|c|}
\hline \multirow{2}{*}{$\begin{array}{l}\text { Characteristics } \\
\text { Patients (n) }\end{array}$} & \multicolumn{2}{|c|}{ SOF/RBV patients } & \multicolumn{2}{|c|}{ SOF/SMV patients } \\
\hline & NR 5 & Relapses 6 & NR 3 & Relapses 5 \\
\hline \multicolumn{5}{|l|}{$\operatorname{Sex}(M / F)$} \\
\hline Patients (N/Ex) & $3 / 2$ & $3 / 3$ & $2 / 1$ & $2 / 3$ \\
\hline FIB-4 & $2 / 3$ & $2 / 4$ & $2 / 1$ & $3 / 2$ \\
\hline F0-1 & 1 & 2 & 0 & 1 \\
\hline F3-4 & 4 & 4 & 3 & 4 \\
\hline \multicolumn{5}{|l|}{ HCV genotype, $n(\%)$} \\
\hline $4 \mathrm{a}$ & 3 & 3 & 2 & 3 \\
\hline 40 & 1 & 2 & 0 & 2 \\
\hline $4 \mathrm{n}$ & 1 & 1 & 1 & 0 \\
\hline \multicolumn{5}{|l|}{ IL28B genotype, n (\%) } \\
\hline $\mathrm{CC}$ & 1 & 2 & 1 & 2 \\
\hline Non-CC & 4 & 4 & 2 & 3 \\
\hline HCV RNA n $(\%)<800,000 \mathrm{IU} / \mathrm{mL}$ & 4 & 6 & 3 & 5 \\
\hline HCV RNA n $(\%)>800,000 \mathrm{IU} / \mathrm{mL}$ & 0 & 0 & 1 & 0 \\
\hline
\end{tabular}

NR, non-response; $M$, male; F, female; $N$, naive; Ex, experienced; IL28B, interleukin 28; PCR, polymerase chain-reaction; SOF, sofosbuvir; SMV, simeprevir; RBV, ribavirin

Supplementary Table 2 The virological response and treatment failure rates among SOF/RBV and SOF/SMV patients according to cirrhosis

\begin{tabular}{|c|c|c|c|c|c|c|}
\hline \multirow{2}{*}{$\begin{array}{l}\text { Parameters } \\
\text { Patients (n) }\end{array}$} & \multirow{2}{*}{$\begin{array}{c}\text { Overall } \\
\text { Patients } \\
\text { Group } 1 \\
101\end{array}$} & \multicolumn{2}{|c|}{$\begin{array}{l}\text { SOF/RBV } \\
\text { Group } 1\end{array}$} & \multirow{2}{*}{$\begin{array}{c}\text { Overall } \\
\text { Patients Group } 2 \\
100\end{array}$} & \multicolumn{2}{|c|}{$\begin{array}{l}\text { SOF/SMV } \\
\text { Group } 2\end{array}$} \\
\hline & & Non-C 76 & Cirrhotic 25 & & Non-C 78 & Cirrhotic 22 \\
\hline $\begin{array}{l}\text { A-Virological response: } \\
\text { HCV RNA, SVR12, n (\%) }\end{array}$ & 90 & 68 & 21 & 92 & 72 & 20 \\
\hline $\begin{array}{l}\text { a-naïve, } n \\
\text { b-experienced, } n\end{array}$ & $\begin{array}{l}53 \\
48\end{array}$ & $\begin{array}{l}44 \\
32\end{array}$ & $\begin{array}{c}9 \\
16\end{array}$ & $\begin{array}{l}75 \\
25\end{array}$ & $\begin{array}{l}61 \\
17\end{array}$ & $\begin{array}{c}14 \\
8\end{array}$ \\
\hline $\begin{array}{l}\text { B-Virological failure: } \mathrm{n}(\%) \\
\text { a-naïve } \\
\text { b-experienced }\end{array}$ & $\begin{array}{l}11 \\
7 \\
4\end{array}$ & $\begin{array}{c}7(9) \\
5 \\
2\end{array}$ & $\begin{array}{c}4(16) \\
2 \\
2\end{array}$ & $\begin{array}{l}8 \\
6 \\
2\end{array}$ & $\begin{array}{c}5(6) \\
4 \\
1\end{array}$ & $\begin{array}{c}3(14) \\
2 \\
1\end{array}$ \\
\hline 1-Non-response, $\mathrm{n}(\%)$ & 5 & 3 & 2 & 6 & 3 & 3 \\
\hline 2-Relapsers, n (\%) & 6 & 4 & 2 & 2 & 0 & 2 \\
\hline 3-Breakthrough, n (\%) & 0 & 0 & 0 & 0 & 0 & 0 \\
\hline
\end{tabular}

SVR12, follow up 12 weeks after end of treatment. Cirrhotic: cirrhotic treatment-experienced and intention to treat (mITT) or per patients. Non-C, Non cirrhotic patients; Experienced, experienced non-cirrhotic patients. The virological response was based on modified intention to treat or per-protocol analysis $S O F$, sofosbuvir; SMV, simeprevir; RBV, ribavirin; EOT, end of treatment 
Supplementary Table 3 Changes in laboratory values of overall patients receiving SOF/RBV and SOF/SMV regimens

\begin{tabular}{|c|c|c|c|c|}
\hline \multirow[t]{2}{*}{ Parameters } & \multicolumn{2}{|c|}{ SOF/RBV patients } & \multicolumn{2}{|c|}{ SOF/SMV patients } \\
\hline & Baseline & SVR12 & Baseline & SVR12 \\
\hline $\operatorname{ALT}(\mathrm{U} / \mathrm{L})$ & 65.49 & 33.75 & 65.49 & 36.93 \\
\hline (SD) & 16.62 & $7.28^{*}$ & 21.43 & $12.69^{*}$ \\
\hline AST (U/L) & 67.84 & 36.55 & 60.65 & 36.55 \\
\hline (SD) & 15.67 & $7.54^{*}$ & 20.16 & $7.54^{*}$ \\
\hline $\mathrm{HB}(\mathrm{mg} / \mathrm{mL})$ & 12.45 & 12.65 & 12.68 & 10.85 \\
\hline (SD) & 1.26 & 1.30 & 1.35 & $0.79^{*}$ \\
\hline Platelets $\times 10^{3} / \mathrm{mm}^{3}$ & 191.35 & 200.14 & 184.32 & 181.18 \\
\hline (SD) & 72.57 & 82.45 & 60.95 & 45.23 \\
\hline HCV RNA (IU) $\left(\times 10^{3}\right)$ & 539.62 & 6.24 & 472.87 & 15.83 \\
\hline (SD) & 33.25 & $1.96^{*}$ & 30.69 & $2.60^{*}$ \\
\hline
\end{tabular}

${ }^{*}$ Denotes a statistically significant difference between baseline and SVR12. Data are expressed as means \pm SD are represented

SOF, sofosbuvir; SMV, simeprevir; RBV, ribavirin; ALT, alanine aminotransferase; AST, aspartate aminotransferase; HB, hemoglobin; SVR12; sustained virological response 12 weeks after the end of treatment 